\title{
On the Impact of Meteorological Conditions on the Initiation of Upward Lightning Flashes from Tall Structures
}

\author{
A. Mostajabi, A. Sunjerga, F. Rachidi \\ Electromagnetic Compatibility Laboratory \\ Swiss Federal Institute of Technology (EPFL) \\ 1015 Lausanne, Switzerland
}

\author{
M. Azadifar, A. Smorgonskiy, M. Rubinstein \\ Institute for Information and Communication Technologies \\ University of Applied Sciences of Western Switzerland \\ 1400 Yverdon-les-Bains, Switzerland
}

\author{
G. Diendorfer \\ ALDIS Department \\ OVE Service GmbH \\ 1010 Vienna, Austria
}

\begin{abstract}
Upward lightning flashes that originate from tall grounded structures have been classified as either 'self-triggered' or 'other-triggered' based on preceding lightning events in their vicinity, i.e. strokes or pulses from cloud-to-ground (CG) or intracloud (IC) discharges occurring around the tower. A total of 165 upward flashes recorded between March 2015 to July 2016 at the Säntis Tower in the eastern Swiss Alps are analyzed considering the related meteorological conditions. The results are compared to similar previous studies to reveal some general ideas on how meteorological conditions influence the initiation of selfand other- triggered upward flashes.
\end{abstract}

Keywords- upward lightning; self- and other triggered lightning; meteorological conditions.

\section{INTRODUCTION}

Studies on lightning activity and related meteorological conditions can be found in the literature since 1960 [1]-[16]. For example, in [1] and [2], indicated variations in the nature of the electric field changes due to lightning discharges are discussed. The attributed changes in meteorological parameters are then presented in order to relate electrical with meteorological parameters. The synoptic situations associated with thunderstorms that initiate upward leaders from the tall towers were studied by Bosart et al. in [4]. More recently, the meteorological conditions related to a winter lightning strike to a 50-m tall weather radar tower were described in [13]. That study looked specifically at the relation between the weather conditions and the accumulation of charge that leads to the initiation of upward leaders from the radome at the top of the tower.
Upward lightning from tall objects has been classified into two categories: Self-triggered (also called ST flash), in which no other lightning activity occurs within a predefined circular area around the tall object and within a given time interval prior to the flash, and other-triggered (also called OT flashes), which are preceded by lightning activity within predefined time and spatial bounds [17]. According to [15], there could be two modes for preceding lightning activity leading to OT flashes initiation: (i) positive $C G$ return strokes propagating through previous leader channels near the tall object, or (ii) the overhead proximity of horizontally propagating negative stepped leaders from either intracloud flashes (ICs) or positive cloud to ground flashes (CGs). After the classification was first proposed by Wang et al. [17] in 2008, several researchers have discussed different initiation conditions for ST and OT flashes from tall objects, e.g. [15], [18]-[26]. A number of studies have addressed the effect of meteorological conditions on the initiation mechanisms of ST and OT upward lightning flashes [15], [17], [21], [27]-[30]. In [28], high speed camera observations and electric field measurements were used along with an assumed cloud structure to analyze the upward lightning mechanisms. In the work of Zhou et al. [27], a comparison of meteorological parameters associated with ST and OT flashes was carried out for a total of 205 flashes recorded during 2005 to 2009 at the Gaisberg Tower. The authors concluded that lower ambient temperature was propitious for ST flash initiation and they found no correlation between wind speed and upward lightning initiation in [27]. Smorgonskiy et al. [2015] presented an analysis of the seasonal and temperature variations of self-triggered and other-triggered flashes at the Säntis Tower, and compared it with observations in Rapid City and Gaisberg. Their study suggests that the mechanism of upward flash initiation features a strong seasonal variation. 
In this study, the meteorological conditions during 165 upward lightning flashes recorded at the Säntis Tower in the eastern Swiss Alps during March 2015 to July 2016 are presented. Each flash is classified into OT or ST according to the existence or absence of lightning activity recorded by the European Cooperation for Lightning Detection (EUCLID) in the vicinity of the Tower and within a specified time interval before the upward tower flash.

The paper is organized as follows: Section II briefly reviews the obtained meteorological and lightning data in the Säntis area from MeteoSwiss, EUCLID, and the instrumentation at the Säntis Tower. The discussion and interpretation of the results are presented in Section III. Finally, conclusions are given in Section IV.

\section{DATA}

\section{A. Meteorological Data Measurement by MeteoSwiss}

Meteorological data have been recorded at the Säntis meteorological station since 1884. The station is situated on top of the Säntis mountain, close to the Säntis Tower location. In this study, data on surface air temperature, wind speed, air pressure at station level (QFE), and relative air humidity were obtained from the Swiss Federal Office of Meteorology and Climatology (MeteoSwiss) to define the meteorological conditions at the time of each event. The granularity level of the data is 10 minutes and the value for the starting point of each ten-minute interval is assigned to the whole interval. This might not cause any significant error since the rate of change for these parameters is usually longer than these time scales.

\section{B. Current Measurement System at the Säntis Tower}

The 124-m tall Säntis Tower has been instrumented since May 2010 for the measurement of lightning currents with highresolution sampling over long observation windows. The analog outputs of the sensors are relayed to a digitizing system by means of optical fiber links. The system allows over-the-Internet remote maintenance, monitoring, and control.

A PXI platform with a current sampling rate of $50 \mathrm{MS} / \mathrm{s}$ is used to digitize and record measured waveforms. The lightning current records are $2.4 \mathrm{~s}$ long with a pre-trigger delay of $960 \mathrm{~ms}$.

In 2013-2014, updates were made to the overall measuring system. More details on the instrumentation system can be found in [31]-[35].

\section{EUCLID Lightning Location System}

The EUCLID lightning location network provided the location data for cloud-to-ground and intra-cloud lightning activity in the vicinity of the Säntis Tower. Information on the EUCLID system can be found in [36], [37]. During the overlapping period with the flashes measured at the Säntis Tower (March 2015 to July 2016), a total of 30733 events were recorded by the EUCLID system within a radius of $30 \mathrm{~km}$ from Säntis Tower.

\section{ANALYSIS AND RESULTS}

\section{A. Categorization of the Flashes as Other-Triggered (OT) or Self-Triggered (ST)}

The classification of the flashes as other- or self-triggered was done in this study according to the occurrence, as detected by EUCLID, of any lightning activity satisfying both temporal and special criteria. A flash was classified as other-triggered if there was at least one EUCLID event detected both, within a chosen time interval $\Delta t=5 \mathrm{~s}$ before the start of the upward leader and inside a circular radius of $\Delta \mathrm{r}=30 \mathrm{~km}$ centered around the tower. Other flashes are considered to belong to the selftriggered category. The time reference was set to the beginning of the upward leader in flashes recorded at the Säntis Tower so that no other components of the flash, for example ICC pulses, would be misjudged as triggering events. During the 17 -month time span from March 2015 to July 2016, 169 flashes were recorded at the Säntis Tower, out of which 165 were recognized as upward flashes. A total of 24 out of the 165 upward flashes were classified as other-triggered (14.5\%) and 141 were classified as self-triggered $(85.5 \%)$. In terms of polarity, 144 out of the complete set of 165 upward flashes were negative, 12 positive, and 9 bipolar upward flashes. For the 24 OT flashes, $75 \%$ were negative, $17 \%$ were positive and $8 \%$ were bipolar. The 141 ST flashes were composed of $89 \%$ negative, $6 \%$ positive and 5\% bipolar.

\section{B. Influence of Meteorological Conditions on ST or OT Flash Initiation}

Fig. 1 shows the monthly distribution of self- and othertriggered upward flashes during the studied period [38] in this paper, from March 2015 to July 2016. It can be seen that all OT flashes occurred during the convective season (May to August), with more than $83 \%$ of them occurring in July. Although, contrary to OT flashes, some of the ST flashes happened during the non-convective season (September to April), the majority happened during the summer with the maximum number of flashes occurring in June.

A histogram of OT and ST flashes as a function of the surface air temperature is presented in Fig. 2. The mean value for the ST flashes is $-0.2^{\circ} \mathrm{C}$ compared to $8.2^{\circ} \mathrm{C}$ for OT flashes, suggesting that ST flashes occur at lower ambient temperature. This result is consistent with the study of Zhou et al. in [27], where 84 out of $96(88 \%)$ of ST flashes occurred when the surface air temperature was below $0{ }^{\circ} \mathrm{C}$ and 22 out of $25(88 \%)$ of the recorded OT flashes occurred for surface air temperatures above $5{ }^{\circ} \mathrm{C}$. The obtained results are also consistent with the analysis presented in [38], in which it was shown that the average temperature for ST flashes at the Peissenberg Tower was about $1.65^{\circ} \mathrm{C}$. For OT flashes, Heidler and Paul [38] did not give any data on temperature but all of the OT flashes in their dataset occurred during the summer. Zhou et al. [27] further pointed out that low ambient temperatures may be associated with lower-than-normal cloud base heights and lower-thannormal freezing heights. The decrease in the height of the cloud may then result in intensification of the electric field and an increase in the probability of upward flashes. 


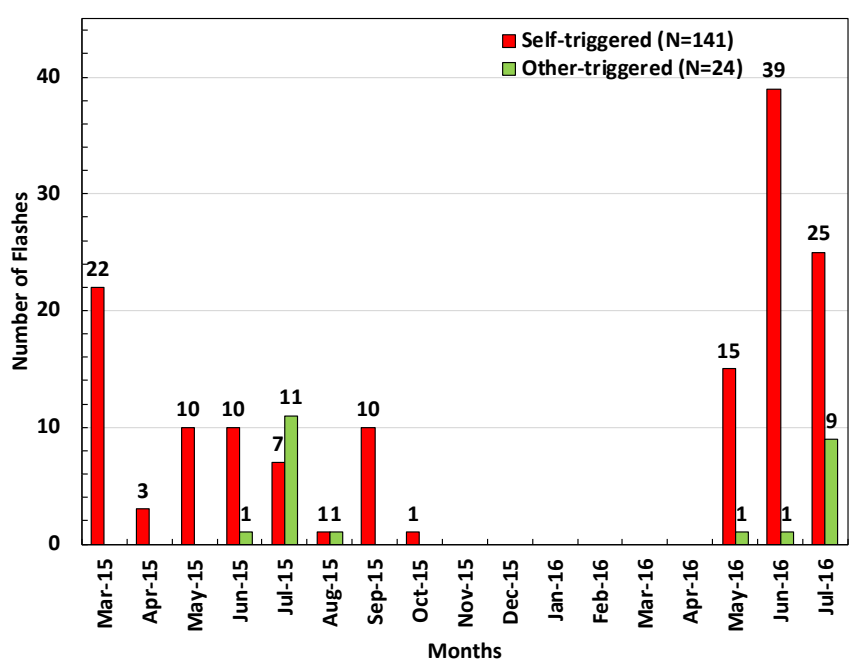

Figure 1. Monthly distribution of self- and other- triggered upward flashes recorded at the Säntis Tower between March 2015 to July 2016.

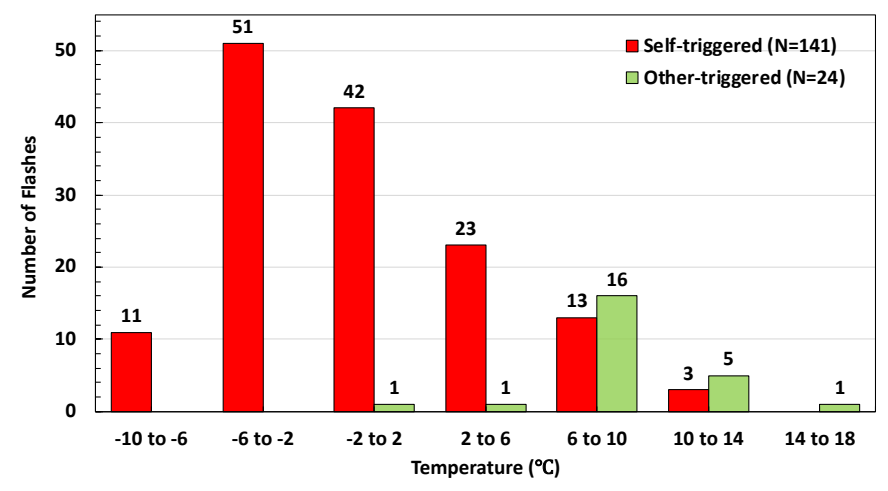

Figure 2. Histogram of the studied self- and other-triggered upward flashes as a function of the surface air temperature at the Säntis meteorological station.

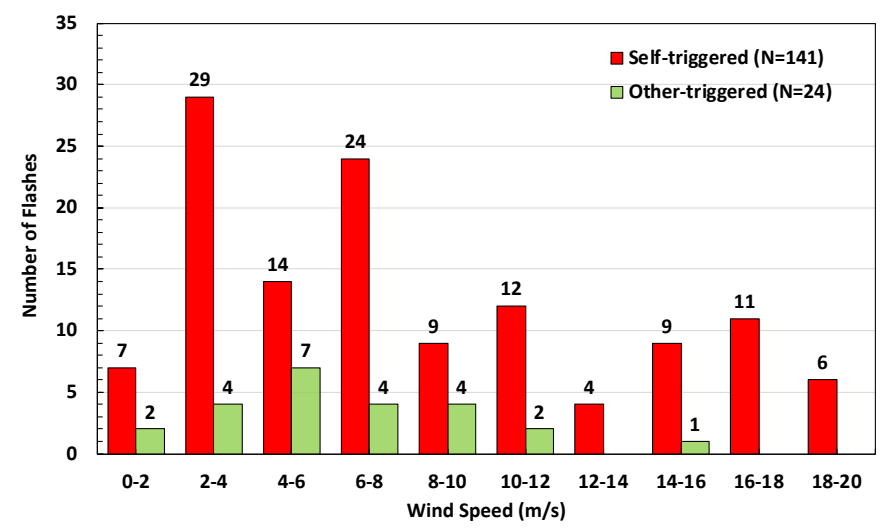

Figure 3. Histogram of the studied self- and other-triggered upward flashes as a function of wind speed at the Säntis meteorological station.

Other meteorological parameters in the Säntis Tower region, including wind speed, air pressure at station level (QFE), and relative humidity are presented, respectively, in Fig. 3 to Fig. 5. The wind speed data for 18 ST flashes were not available from MeteoSwiss and they are not included in Fig. 3.
The results for wind speed at Säntis (see Fig. 3) suggest that the overall number of tower flashes tends to decrease as the wind speed increases. In order to investigate the influence of the wind speed on the initiation of ST and OT flashes, the percentage of ST flashes is presented in Fig. 6 as a function of wind speed. For comparison, the same percentage associated with the data at the Gaisberg Tower [27] and in Uchinada-chou [20] are presented in the same figure. It can be observed that the percentage of ST flashes as a function of the wind speed shows an increasing trend for all the three locations. The stronger variations in the Uchinada-chou data might be due to the limited number of recorded events (29 flashes), compared to the other two datasets (121 flashes in Gaisberg and 147 flashes in Säntis). In addition, it can also be seen that in the Säntis and the Gaisberg data, beyond a certain wind speed level, only ST flashes are observed.

It is worth noting that the classification of flashes into ST and OT using lightning location systems might be affected by inaccuracies [39] in the sense that the number of OT flashes from LLS data can be underestimated since cloud discharge activity may sometimes be missed by Lightning Location Systems.

A summary of statistical parameters regarding the datasets in Fig. 2 to Fig. 5 is presented in Table I. For comparison, the

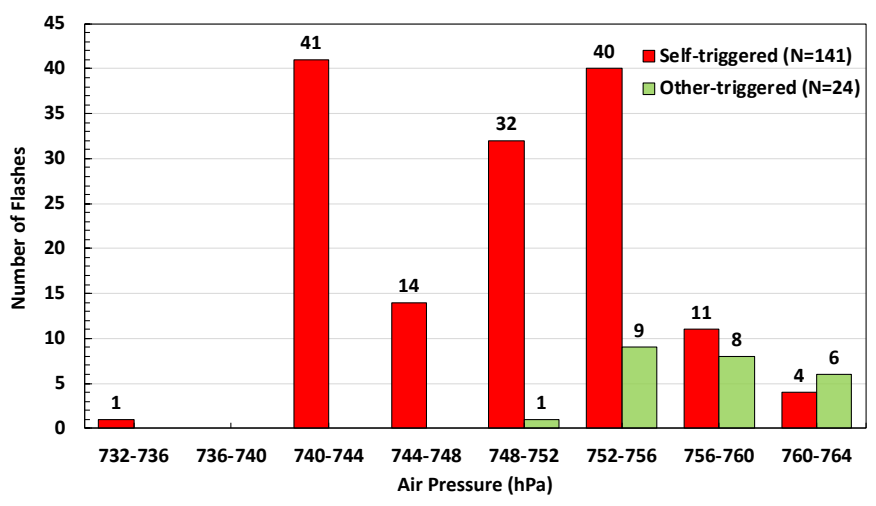

Figure 4. Histogram of the studied self- and other-triggered upward flashes as a function of air pressure (QFE) at the Säntis meteorological station level.

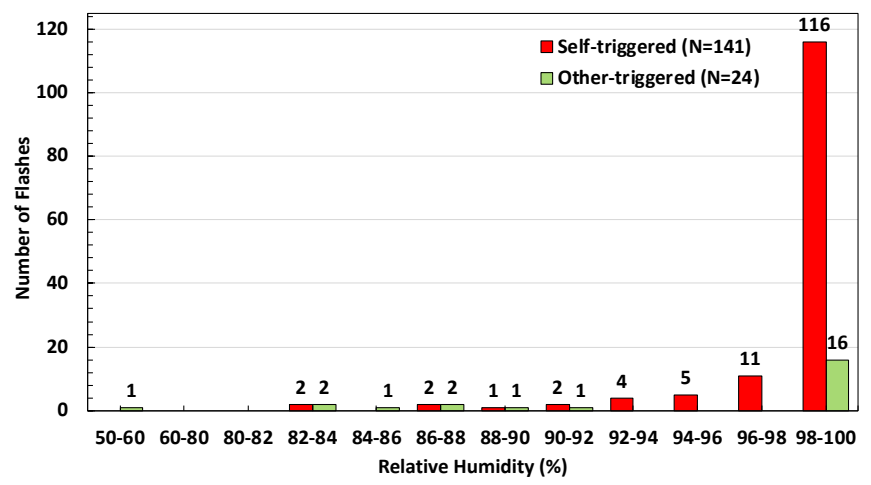

Figure 5. Histogram of the studied self- and other-triggered upward flashes as a function of the relative air humidity at the Säntis meteorological station. 


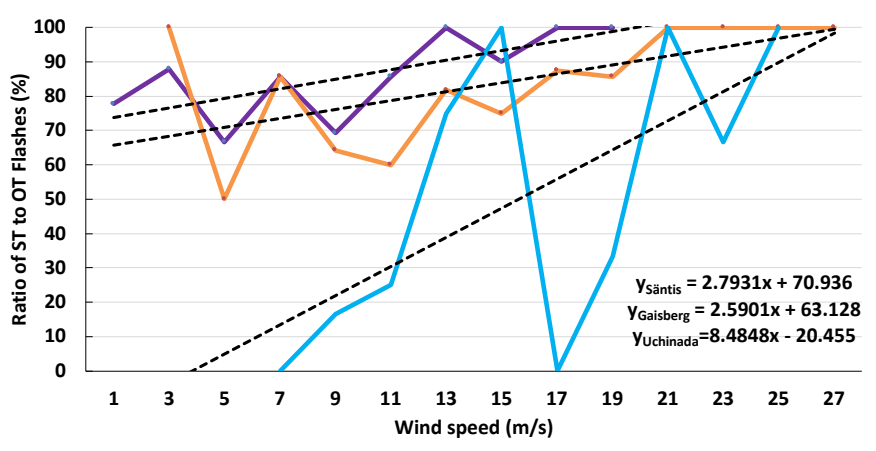

-Säntis ( $\mathrm{N}=147$ flashes) -Gaisberg ( $\mathrm{N}=121$ flashes) -Uchinada-chou ( $\mathrm{N}=29$ flashes)

Figure 6 . The percentage of ST flashes as a function of wind speed for the recorded flashes at the Säntis Tower, the Geisberg Tower [27], and the lightning protection tower of a windmill in Uchinada-chou [20]. The linear trending lines with the attributed equations are also shown for all three datasets.

TABLE I. SUMMERIZED STATISTICAL ANALYSIS OF METEOROLOGICAL PARAMETERS AT THE SÄNTIS TOWER.

\begin{tabular}{|c|c|c|c|c|c|c|c|c|}
\hline \multirow[b]{2}{*}{ Flash type } & \multicolumn{2}{|c|}{$\begin{array}{c}\text { Temperature } \\
\left({ }^{\circ} \mathrm{C}\right)\end{array}$} & \multicolumn{2}{|c|}{$\begin{array}{l}\text { Wind } \\
\text { speed } \\
(\mathrm{m} / \mathbf{s})\end{array}$} & \multicolumn{2}{|c|}{$\begin{array}{l}\text { Air pressure } \\
\text { (QFE) (hPa) }\end{array}$} & \multicolumn{2}{|c|}{$\begin{array}{c}\text { Relative } \\
\text { humidity } \\
(\%)\end{array}$} \\
\hline & ST & OT & ST & OT & ST & OT & ST & OT \\
\hline $\begin{array}{c}\text { Arithmetic } \\
\text { mean }\end{array}$ & -0.2 & 8.3 & 7.3 & 6.2 & 749.4 & 757.9 & 98.7 & 93.8 \\
\hline Maximum & 10.7 & 17.2 & 19.9 & 15.8 & 762.6 & 763.1 & 100 & 100 \\
\hline Minimum & -9.9 & 0.9 & 0.7 & 0.9 & 736 & 751.7 & 82.7 & 51.1 \\
\hline
\end{tabular}

TABLE II. SUMMERIZED STATISTICAL ANALYSIS OF METEOROLOGICAL PARAMETERS AT THE GAISBERG TOWER [27].

\begin{tabular}{|c|c|c|c|c|c|c|c|c|}
\hline \multirow[b]{2}{*}{ Flash type } & \multicolumn{2}{|c|}{$\begin{array}{c}\text { Temperature } \\
\left({ }^{\circ} \mathrm{C}\right)\end{array}$} & \multicolumn{2}{|c|}{$\begin{array}{l}\text { Wind } \\
\text { speed } \\
(\mathrm{m} / \mathrm{s})\end{array}$} & \multicolumn{2}{|c|}{$\begin{array}{l}\text { Air pressure } \\
\text { (QFE) (hPa) }\end{array}$} & \multicolumn{2}{|c|}{$\begin{array}{c}\text { Relative } \\
\text { humidity } \\
(\%)\end{array}$} \\
\hline & $S T$ & $O T$ & $S T$ & $O T$ & $S T$ & $O T$ & $S T$ & $O T$ \\
\hline $\begin{array}{l}\text { Arithmetic } \\
\text { mean }\end{array}$ & -2.8 & 11.1 & 13.3 & 12 & 865.4 & 871.9 & 94.6 & 91 \\
\hline Maximum & 15.5 & 15.7 & 26.7 & 18.3 & 879.9 & 876.6 & 96.7 & 95.7 \\
\hline Minimum & -13.4 & 2.6 & 2.6 & 5.6 & 850 & 864.2 & 77.8 & 85.2 \\
\hline
\end{tabular}

statistical parameters for the Gaisberg Tower data given in [27] are presented in Table II. The two data sets show good consistency in terms of air pressure. In both cases (see Table I and Table II), the arithmetic mean air pressure for ST flashes is lower than for OT flashes. As seen in Fig. 4, the range of pressures for which OT flashes are observed is concentrated toward the higher pressures (748 $\mathrm{hPa}$ and beyond) and it is considerably narrower than for ST flashes.

Furthermore, it is seen in Table I and Table II that in both studies the maximum and minimum recorded wind speeds during the whole studied period belong to the ST category.

A histogram of the numbers of OT and ST flashes as a function of the relative humidity is shown in Fig. 5. It can be seen in that figure that ST and OT flashes tend to occur in more humid weather. It can also be observed that $33 \%$ of OT flashes occurred in conditions when the humidity was below $92 \%$, while this percentage for ST flashes is just 4\%. The total number of tower flashes is much higher for humidity levels approaching $100 \%$ than for lower values.

\section{CONCLUSIONS}

A study of the influence of meteorological conditions on the initiation of self- and other-triggered upward lightning flashes at the Säntis Tower was presented. The obtained results were found to be consistent with previous observations in Austria (Gaisberg Tower) and Japan (Uchinada-chou).

It was shown that ST flashes are mainly observed in lower ambient temperatures.

The percentage of ST flashes as a function of the wind speed shows an increasing trend. For wind speeds of $12 \mathrm{~m} / \mathrm{s}$ and higher, out of 31 upward flashes, 30 were of ST category, and beyond $17 \mathrm{~m} / \mathrm{s}$, only ST flashes were observed.

The range of pressures for which OT flashes are observed is concentrated toward the higher pressures ( $748 \mathrm{hPa}$ and beyond) and it is considerably narrower than for ST flashes.

\section{ACKNOWLEDGMENT}

This work was supported in part by the Swiss National Science Foundation (Project No. 200020_175594) and the European Union's Horizon 2020 research and innovation program under grant agreement No 737033-LLR.

\section{REFERENCES}

[1] M. Brook and N. Kitagawa, "Some Aspects of Lightning Activity and Related Meteorological Conditions," J. Geogr. Res., vol. 65, 1960.

[2] N. Kitagawa and M. Brook, "A comparison of intracloud and cloud-toground lightning discharges," J. Geophys. Res., vol. 65, no. 4, pp. 11891201, Apr. 1960.

[3] R. F. Griffiths and J. Latham, "Electrical corona from ice hydrometeors," O. J. R. Meteorol. Soc., vol. 100, no. 424, pp. 163-180, Apr. 1974.

[4] L. F. Bosart, T. J. Chen, R. E. Orville, and H. P. Roesli, "A preliminary study of the synoptic conditions associated with lightning flashes over Mt. San Salvatore, Lugano, Switzerland," Tellus, vol. 26, no. 4, pp. 495-505, Aug. 1974.

[5] R. L. Holle, A. I. Watson, R. E. Lopez, and R. Ortiz, "Meteorological aspects of cloud-to-ground lightning in the Kennedy Space Center region," Jan. 1988.

[6] K. Michimoto, "A Study of Radar Echoes and their Relation to Lightning Discharge of Thunderclouds in the Hokuriku District," J. Meteorol. Soc. Japan. Ser. II, vol. 69, no. 3, pp. 327-336, 1991.

[7] Y. Maekawa, S. Fukao, Y. Sonoi, and F. Yoshino, "Distribution of ice particles in wintertime thunderclouds detected by a $C$ band dual polarization radar: A case study," J. Geophys. Res., vol. 98, no. D9, p. 16613, Sep. 1993.

[8] N. Kitagawa and K. Michimoto, "Meteorological and electrical aspects of winter thunderclouds," J. Geophys. Res., vol. 99, no. D5, p. 10713, May 1994.

[9] A. R. Moller et al., "The Operational Recognition of Supercell Thunderstorm Environments and Storm Structures," Weather Forecast., vol. 9, no. 3, pp. 327-347, Sep. 1994.

[10] D. Petersen, M. Bailey, W. H. Beasley, and J. Hallett, "A brief review of the problem of lightning initiation and a hypothesis of initial lightning leader formation," J. Geophys. Res., vol. 113, no. D17, p. D17205, Sep. 2008.

[11] W. A. Lyons et al., "The Meteorological and Electrical Structure of TLE- 
Producing Convective Storms," in Lightning: Principles, Instruments and Applications, Dordrecht: Springer Netherlands, 2009, pp. 387-415.

[12] J. Lopez, I. Hernaez, and J. Montanya, "Study of single-flash thunderstorms over wind farms in the Basque Country," in 2012 International Conference on Lightning Protection (ICLP), 2012, pp. 1-5.

[13] J. López, J. Montanyà, M. Maruri, D. De la Vega, J. A. Aranda, and S. Gaztelumendi, "Lightning initiation from a tall structure in the Basque Country," Atmos. Res., vol. 117, pp. 28-36, Nov. 2012.

[14] T. A. Warner et al., "UPLIGHTS: Upward Lightning Triggering Study," Bull. Am. Meteorol. Soc., vol. 94, no. 5, pp. 631-635, May 2013.

[15] W. A. Lyons and T. E. Nelson, "Meteorological Aspects of Two Modes of Lightning Triggered Upward Lightning (LTUL) Events in SpriteProducing MCSs," in 5th Intl. Lightning Meteorology Conference, 2014.

[16] S. YOSHIDA, T. WU, T. USHIO, and Y. TAKAYANAGI, "Lightning Observation in 3D Using a Multiple LF Sensor Network and Comparison with Radar Reflectivity," Electr. Eng. Japan, vol. 194, no. 3, pp. 1-10, Feb. 2016.

[17] D. Wang, N. Takagi, T. Watanabe, H. Sakurano, and M. Hashimoto, "Observed characteristics of upward leaders that are initiated from a windmill and its lightning protection tower," Geophys. Res. Lett., vol. 35, no. 2, p. L02803, Jan. 2008

[18] D. Wang, N. Takagi, and Y. Takaki, "A comparison between selftriggered and other-triggered upward lightning discharges," in 2010 30th International Conference on Lightning Protection (ICLP), 2010, pp. 1-4.

[19] H. Zhou, G. Diendorfer, R. Thottappillil, H. Pichler, and M. Mair, "Measured current and close electric field changes associated with the initiation of upward lightning from a tall tower," J. Geophys. Res. Atmos., vol. 117 , no. D8, p. n/a-n/a, Apr. 2012

[20] D. Wang and N. Takagi, "Characteristics of Winter Lightning that Occurred on a Windmill and its Lightning Protection Tower in Japan," IEEJ Trans. Power Energy, vol. 132, no. 6, pp. 568-572, Jun. 2012.

[21] T. A. Warner, K. L. Cummins, and R. E. Orville, "Upward lightning observations from towers in Rapid City, South Dakota and comparison with National Lightning Detection Network data, 2004-2010," $J$ Geophys. Res. Atmos., vol. 117, no. D19, p. n/a-n/a, Oct. 2012.

[22] R. Daher, M. Azadifar, A. Smorgonskiy, J. Zuber, and R. M., "A Study of Upward Flashes Initiated at the Säntis Tower," in Asia Electromagnetics International Symsposium ASIAEM, 2017.

[23] A. Smorgonskiy, A. Tajalli, F. Rachidi, M. Rubinstein, G. Diendorfer, and H. Pichler, "Analysis of lightning events preceding upward flashes from Gaisberg and Säntis Towers," in 2014 International Conference on Lightning Protection (ICLP), 2014, pp. 1382-1385.

[24] M. Rubinstein, J. Zuber, A. Smorgonskiy, F. Rachidi, and G. Diendorfer, "Correlation vs. causality in other-triggered upward lightning in tower flashes," in 201633 rd International Conference on Lightning Protection (ICLP), 2016, pp. 1-4.

[25] M. Rubinstein, A. Smorgonskiy, F. Rachidi, and J. Zuber, "On the Classification of Tower Flashes as Self-Initiated and Other-Triggered," 2015.
[26] C. Schumann, M. M. F. Saba, T. A. Warner, and M. A. S. Ferro, "Upward flashes triggering mechanisms," in 2017 International Symposium on Lightning Protection (XIV SIPDA), 2017, pp. 304-307.

[27] H. Zhou, G. Diendorfer, R. Thottappillil, H. Pichler, and M. Mair, "The influence of meteorological conditions on upward lightning initiation at the Gaisberg Tower," 2014 Int. Conf. Light. Prot. ICLP 2014, pp. 1162 1165,2014

[28] R. Jiang et al., "Characteristics of upward lightning from a 325-m-tall meteorology tower," Atmos. Res., vol. 149, pp. 111-119, Nov. 2014.

[29] S. Yuan, R. Jiang, X. Qie, D. Wang, Z. Sun, and M. Liu, "Characteristics of Upward Lightning on the Beijing $325 \mathrm{~m}$ Meteorology Tower and Corresponding Thunderstorm Conditions," J. Geophys. Res. Atmos., vol. 122, no. 22, p. 12,093-12,105, 2017.

[30] A. Smorgonskiy, A. Tajalli, F. Rachidi, M. Rubinstein, G. Diendorfer, and H. Pichler, "An analysis of the initiation of upward flashes from tall towers with particular reference to Gaisberg and Säntis Towers," $J$. Atmos. Solar-Terrestrial Phys., vol. 136, pp. 46-51, 2015.

[31] M. Azadifar, M. Paolone, D. Pavanello, F. Rachidi, C. Romero, and M. Rubinstein, "An Update on the Instrumentation of the Säntis Tower in Switzerland for Lightning Current Measurements and Obtained Results," in CIGRE Int. Colloquium on Lightning and Power Systems, 2014.

[32] C. Romero, A. Mediano, A. Rubinstein, F. Rachidi, A. Rubinstein, and M. Paolone, "Measurement of Lightning Currents Using a Combination of Rogowski Coils and B-Dot Sensors," J. Light. Res., vol. 4, pp. 71-77, 2012.

[33] C. Romero, F. Rachidi, R. M., P. M., R. V. A., and D. Pavanello, "Positive Lightning Flashes Recorded on the Säntis Tower in 2010 and 2011," $J$. Geophys. Res., p. 12'879-12'892, 2013.

[34] C. Romero et al., "A system for the measurements of lightning currents at the Säntis Tower," Electr. Power Syst. Res., vol. 82, no. 1, pp. 34-43, 2012.

[35] C. Romero, F. Rachidi, M. Paolone, and S. Member, "Statistical Distributions of Lightning Currents Associated With Upward Negative Flashes Based on the Data Collected at the Säntis (EMC) Tower in 2010 and 2011," IEEE Trans. Power Deliv., vol. 28, no. 3, pp. 1804-1812, 2013.

[36] M. Azadifar et al., "Evaluation of the performance characteristics of the European Lightning Detection Network EUCLID in the Alps region for upward negative flashes using direct measurements at the instrumented Säntis Tower," J. Geophys. Res. Atmos., 2016.

[37] W. Schulz, G. Diendorfer, S. Pedeboy, and D. R. Poelman, "The European lightning location system EUCLID - Part 1: Performance analysis and validation," Nat. Hazards Earth Syst. Sci, vol. 16, pp. 595-605, 2016.

[38] F. H. Heidler and C. Paul, "Some Return Stroke Characteristics of Negative Lightning Flashes Recorded at the Peissenberg Tower," IEEE Trans. Electromagn. Compat., vol. 59, no. 5, pp. 1490-1497, Oct. 2017.

[39] A. Sunjerga et al., "Self-Initiated versus Triggered Upward Flashes. What Can Lightning Mapping Array Data Tell Us?," Submitted to: International Conference on Lightning Protection, 2018. 